\title{
Information Diffusion and the Lead-Lag Relationship between Small and Large Size Portfolios: Evidence from an Emerging Market
}

\author{
Anastassios A. Drakos ${ }^{1}$, Panayiotis F. Diamandis ${ }^{1} \&$ Georgios P. Kouretas ${ }^{1}$ \\ ${ }^{1}$ Department of Business Administration, Athens University of Economics and Business, Athens, Greece \\ Correspondence: Georgios P. Kouretas, Department of Business Administration, Athens University of \\ Economics and Business, 76 Patission Street, GR-10434, Athens, Greece. Tel: 302-108-203-277. E-mail: \\ Kouretas@aueb.gr
}

Received: August 4, 2015

Accepted: September 3, 2015

Online Published: October 25, 2015

doi:10.5539/ijef.v7n11p25

URL: http://dx.doi.org/10.5539/ijef.v7n11p25

\begin{abstract}
This paper investigates whether lead-lag patterns exist between small and large size portfolios constructed from stocks traded in an emerging market, the Cyprus Stock Exchange (CSE). We examine this relation in both its short-run by using the correlation-based approach of Lo and MacKinlay (1990) and its long-run by employing the cointegration-based methodology of Kanas and Kouretas (2005). Furthermore, on finding that cointegration exists we then use the estimated error correction models (ECMs) to obtain out-of-sample forecasts of small-firm portfolio returns and it is shown that these ECMs have superior forecasting performance relative to models without the error correction terms. The main finding of our analysis is that a lead-lag effect was established between small and large size portfolios for the Cyprus equity market in both the short-run and the long-run.
\end{abstract}

Keywords: lead-lag effect, cross correlation; cointegration; stock returns predictability; size-sorted portfolios

\section{Introduction}

Lo and MacKinlay (1990) established an important lead-lag relation between small and large size portfolios returns using weekly data from the NYSE. Using the cross-autocorrelation analysis they show that returns of larger capitalization stocks lead and those of smaller capitalization stocks follow. Furthermore, they suggested that such a lead-lag relationship can be considered as a source of contrarian profits. The analysis of correlations of returns is very important in order to understand the workings and the structure of markets. Given such relationship, Lo and MacKinlay (1990) argue that when there is a difference in the speed of reaction to information among the stocks then a contrarian strategy may lead to profits even in the case where no stock overreacts to information. The implication of the existence of such relationship relates to the ability of investors to forecast the returns of small-firm portfolios based on the returns of large-firm portfolios and that contradicts the efficient market hypothesis. These findings have resulted to an intense discussion during the last fifteen years (Note 1, Note 2).

However, Boudoukh et al. (1994), Badrimath et al. (1995) and Jegadeesh and Titman (1995) have questioned this evidence and they argue that it is not clear that there is a positive cross-correlation between lagged returns of large-firm portfolios with current returns of small-firm portfolios. Furthermore, Campbell et al. (1997) argued that this relation implies a rather complicated information transmission mechanism between large-and small-firm portfolio returns and therefore we are still far from having a complete understanding of their nature and sources.

Several explanations have been offered for the existence of this provoking relationship. Lo and MacKinlay (1990) relate this evidence to the way that market news are transmitted through the stock prices. They argue that information shocks are first embodied in the large-size portfolios and then with a time lag to the small-size portfolios. Badrinath et al. (1995) provide as a potential explanation of such lead-lag relationship the level of institutional ownership of the firms. Finally, Merton (1987) considers the information set-up cost, a factor which is highly correlated with firm size, as another possible explanation for the presence of a lead-lag relationship.

In this paper we examine the existence of a lead-lag relationship between large-size and small-size portfolios using weekly data for the period 1996 to 2014 from the Cyprus Stock Exchange (CSE). This is an emerging market that was established in March 1996 following the restructuring of the banking and financial sectors in the early 1990s. Moreover, the abolishment of capital controls that took place as part of the requirements to join the 
European Union at that time, led to an increased interest of investors especially in the years 1999 to 2001 when high returns have been recorded for most of the securities traded. However, subsequent dramatic fall of the stock prices led most of investors in frustration. Such behaviour by the investors in the Cyprus Stock Exchange has now been considered as the result of the existence of a rational bubble over the two year period (see Chrysostomidou et al., 2006; and Diamandis, 2014). The CSE has experienced a dramatic change over the last decade, in terms of both trading activity and market operations. The exchange process was modernized, the legal framework has been reformed and the market now provides alternative trading tools (such as the margin account and the operation of market makers). In terms of volume, the trading activity has increased significantly as a result of new listings and secondary offerings. A result of this 'bullish' period has been the need for detecting investment opportunities either in individual securities or in risk-return balanced portfolios of various securities.

However, as a consequence of the recent European debt crisis in March 2013 action was taken when the banking sector of Cyprus nearly collapsed and the Cypriot economy was put under the supervision of the European Commission and the ECB and through a bail-in mechanism the bankrupt banking sector was restructured and capital controls were imposed that only recently were lifted. Thus, once again investors, portfolio managers and hedge funds who seek new investment opportunities in developed and emerging markets are forced to investigate possible patterns in the expected returns of stocks or portfolios, such as the existence of lead-lag effects among size-sorted portfolios in the Cyprus Stock Exchange (Note 3).

Since this market is a relatively new one only a few works have examined its characteristics with respect to market efficiency and stock price volatility. Chrisostomidou et al. (2006) and Diamandis (2014) have shown that the weak form efficient market hypothesis is strongly rejected for the CSE. These studies have documented that CSE follows a pattern where last's period's returns are correlated with today's returns. This finding supports the ability of predictability for CSE which may lead to substantial abnormal profits (Note 4).

As we mentioned above Boudoukh et al. (1994) and Jegadeesh and Titman (1995) have questioned the importance of such lead-lag relationship. They argue that there is little evidence that contrarian strategies can be applied when stock prices exhibit a delayed reaction to common factors. Furthermore, they argue that the major source of any potential contrarian profit that may result from trading strategies is stock price overreaction to firm-specific factors while any lead-lag relationship has a very limited role. ${ }^{5}$ Another explanation for contrarian profits is offered by Conrad and Kaul (1998) who argue that even in markets without frictions we may find evidence of negative autocorrelation and negative cross-correlation between short-term stock returns consistent with time-varying common factors. Finally, Hou (2007) argues that the slow diffusion of industry information is a major cause of the lead-lag effect in stock returns. Specifically, Hou (2007) finds that the lead-lag effect between big firms and small firms is predominantly intra-industry phenomenon. Furthermore, he argues that this effect is driven by sluggish adjustment to negative information, and is robust to alternative determinants of the lead-lag effect. Hou (2007) also provides evidence that the lead-lag effect is related to the post-announcement drift of small firms following the earnings releases of big firms within the industry.

Evidence of lead-lag effect between large and small-size portfolios along with other trading strategies are considered as a cause of rejection of the market efficiency hypothesis, since in informationally efficient markets stock prices fully reflect all available information and therefore it is not possible to make abnormal profits by exploiting past information. According to behavioural finance these abnormal profits is evidence of inefficient markets with the inefficiency being the outcome of investors' herding behaviour as well as irrational reactions of stock prices to news. In contrast those who support the efficient market hypothesis argue that the existence of abnormal profits of contrarian strategies is only due to the lack of structural models like CAPM to take into consideration those time-varying common factors.

Much of the literature on the lead-lag relationship between small and large capitalization stocks have been done on U.S. and U.K. data. However, it is likely that the existence of such a relationship and the realization of abnormal profits as a result of trading strategies could be more evident in emerging markets. Furthermore, during the 1990s we observed a substantial increase in financial uncertainty as a result of the increased volatility that stock returns exhibited in mainly in the emerging markets. This was the outcome of the increased flow of portfolio capital from the mature markets to the emerging markets of the South East Asia and the economies of transition of Central and Eastern European countries. Singh and Weisse (1998) report that during the period 1989-1995 the inflow of funds in emerging markets amounted to 107.6 billion US dollars as opposed to a mere 15.1 billion US dollars in the previous period 1983-1988. This increased capital flow to the emerging markets continued until the recent financial crisis of 2007-2009 that led to a reversal of capital flows due to the liquidation of investment by hedge funds and portfolio managers and a "flight to quality" (Shaghil \& Zlate, 2013; Bluedorn et al., 2013). There are several reasons for these enormous inflow of portfolio funds to the emerging 
markets but certainly the most important was the fact that during the 1990s the mature markets has reached their limitations with respect to profit opportunities and made portfolio managers and institutional investors to look for new opportunities in these new markets. The higher volatility of emerging markets is mainly the result of thin trading, the existence of opportunities for stock price predictability and the participation of small and less sophisticated investors who do not respond instantaneously to information shocks, (Antoniou et al., 1997; Antoniou et al., 2005). It becomes evident therefore that in these markets which are less efficient there is greater possibility for the existence of such an exploitable relationship that can lead to the realization of abnormal profits and hence their characteristics would be of interest to investors and portfolio managers (see Forbes \& Warnock, 2012; Powell, 2013 for a thorough analysis).

We analyze the lead-lag patterns between large-size and small-size firms listed in the CSE in the short-run and in the long-run. The first part of our analysis examines the existence of such a relationship using the correlation-based short run approach which has been initially employed by Lo and MacKinlay (1990) and has been used in most of the subsequent works like Mills and Jordanov (2000). In the second part of the paper we discuss the existence of lead-lag effects between large and small capitalization portfolios in a long-run perspective. To this end we adopt the framework developed by Kanas and Kouretas (2005) who illustrate that lagged information transmission may entail cointegration between the current price of small-firm portfolios and the lagged price of large-firm portfolios.

The main findings of our paper are summarized as follows. First, following Lo and MacKinlay (1990) we were able to establish cross-correlation patterns between size-sorted equity portfolios constructed from the Cyprus Stock Exchange. These patterns are shown to be similar to that found in the US and the UK and other mature and emerging stock markets. Second, following Kanas and Kouretas (2005) we found that there is cointegration between equally weighted size-sorted portfolios and that large-firm portfolio prices are long-run forcing variables for small-firm portfolio prices. This piece of evidence supports the theoretical arguments that in the long-run the lagged one period price of the large size firm leads the contemporaneous price of the small size firm. In addition we were unable to observe the opposite directional effect. A final point of the present analysis concerns the forecasting performance of the estimated error correction models. With the use of standard statistical criteria we clearly show that the forecasting performance of these models is substantially improved compared to the models without the error correction term.

The rest of the paper is organized as follows. Section 2 outlines the construction of the portfolios. Section 3 presents the results of the autocorrelation and cross-correlation. Section 4 discusses the cointegration approach to the lead-lag effect and we present our results. Section 5 reports the forecasting performance of our correction model while conclusions are presented in Section 6.

\section{Data and Portfolio Construction}

The data set for the Cyprus stock market includes weekly compounded returns in order to test for the existence of a lead-lag effect in the prices of size-sorted equity portfolios. The data is obtained from the Cyprus Stock Exchange official database and the DATASTREAM database and used to obtain weekly stock return data for the period January 1997 to December 2014. The data consists of 988 observations of weekly total returns. The calculation of the market value for each company in the sample is done by multiplying the share price of the firm at the end of the year by the total number of outstanding shares at the end of the year. We then sort the firms into five size-portfolios by market value. Finally, for a share to be included in a size-portfolio we require that its shares have been traded for at least one year.

Thus, the first set of five sort size-sorted portfolios was formed using market value at the end of 1996 and these will be the 1997 portfolios. The portfolios are rebalanced at the end of every year in order to include any new listings. For the 1996 size-sorted portfolios, 42 firms are included, while in 2014, the number of eligible companies has grown to 167 . We then construct the five portfolios, using equally weighted weekly returns, calculated from individual share prices for the weeks of each year. Therefore, for a particular year, the equally weighted size-sorted equity portfolio returns are calculated as follows:

$$
R_{p, t}=n^{-1} \sum_{i=1}^{n_{p}}\left(p_{i, t}-p_{i, t-1}\right) / p_{i, t-1}
$$

where $R_{p, t}$ is the return for portfolio $P \quad(p=1,2,3,4,5)$ for week $t, P_{i, t}$ is the price for share $i$ in portfolio $P$ for week $t$, and $n_{p}$ is the number of shares included in portfolio $P$.

Table 1 reports the descriptive statistics for the five portfolios (with portfolio 1 being that with the lowest market 
capitalization and portfolio 5 that with the highest). From these results it is shown that the average return is clearly increases as we move from portfolio 5 down to portfolio 1 . It is also clear that the variance of the returns increases as we move towards the lowest capitalization portfolio. Furthermore, all portfolios are negatively skewed and statistically significant, while portfolios 2 and 4 show evidence of significant excess kurtosis implying fat-tailed behaviour and therefore, all portfolio returns appear to be statistically significant different from normality. Finally, Table 1 reports sample autocorrelations and the Ljung-Box portmanteau statistics for the weekly size portfolios' returns. All portfolios exhibit positive lag one serial correlation. Furthermore, for portfolios 1 and 2 first-order autocorrelation is significant but not for the remaining portfolios. For portfolios 1 and 2 the first-order autocorrelations are approximately 0.2 . For portfolios 3-5 we observe that second-order autocorrelations are statistically significant negative. No other autocorrelation order is significant. Therefore, there is some evidence that investors participating in the Cyprus Stock Exchange "over-react". We also note that the magnitude of the autocorrelations, as it is summarized by the Ljung-Box, Q, portmanteau statistic tends to decrease with the size of the portfolio.

Table 1. Size portfolios: summary statistics for 1997.12-2014.52

\begin{tabular}{lccccc}
\hline Portfolio & 1 & 2 & 3 & 4 & 5 \\
\hline Mean & 0.527890 & 0.392888 & 0.0982056 & 0.074568 & 0.045893 \\
Std. Dev. & 6.117789 & 5.667809 & 4.113356 & 2.335671 & 2.001124 \\
Skewness & -0.127898 & -0.14566 & 0.113324 & -0.28902 & -0.17656 \\
Kurtosis & 1.445612 & 6.338989 & 2.259010 & 10.33266 & 2.20456 \\
Jarque-Bera & 501.2781 & 545.2367 & 651.0908 & 1345.698 & 1678.119 \\
$r_{1}$ & $0.022^{*}$ & $0.025^{*}$ & 0.037 & 0.103 & 0.144 \\
$r_{2}$ & -0.020 & -0.10 & $-0.105^{*}$ & $-0.201^{*}$ & $-0.289^{*}$ \\
$r_{3}$ & 0.031 & 0.067 & 0.089 & 0.090 & 0.56 \\
$r_{4}$ & -0.054 & 0.089 & 0.055 & -0.177 & -0.132 \\
$Q(12)$ & 5.335 & 9.678 & 12.595 & 37.565 & 51.453 \\
$P$-value & 0.039 & 0.019 & 0.02 & 0.00 & 0.00 \\
Observations & 416 & 416 & 416 & 416 & 416 \\
\hline
\end{tabular}

Notes. $r_{i}$ denotes return autocorrelation at lag $i$. Portfolio 1 refers to the lowest capitalization portfolio, while portfolio 5 refers to the highest. (*) denotes statistical significance at the 5 percent critical value under the null hypothesis that returns are white noise. $Q(6)$ is the Ljung-Box portmanteau test statistic for 6 autocorrelations, distributed as $\chi^{2}(6)$ and the $5 \%$ critical value is 12.59 .

\section{Portfolio Correlation Structures}

In this section we follow Lo and MacKinlay (1990), Campbell et al. (1997) and Mills and Jordanov (2000) among others to investigate the cross-correlation patterns in order to show whether a short-run lead-lag effect between small and large capitalization portfolio, with the large size portfolio leading the small size one. Such an approach can provide a further explanation to that offered by works such as those of Lo and MacKinlay (1990) and Boudoukh et al. (1994) who argue that the evidence of serial correlation in small size firms is due to non-synchronous trading. However, Lo et al. (1997) argue that the size of this autocorrelation structure for the smaller size portfolios is substantially large to be solely explained by non-synchronous trading.

In Table 2 we report the cross-autocorrelations matrices for the five equally weighted size-sorted equity portfolios. The top of Table 2 refers to matrix $Y_{0}$ which shows the contemporaneous cross-autocorrelations, and we observe that the correlation between the portfolios increases the closer by size are these portfolios. Additionally, $Y_{1}$ and $Y_{2}$ define the first and second order autocorrelations between portfolios. Although the results for the contemporaneous autocorrelations are those expected a priori the results of the lagged autocorrelations need a closer look. The picture that emerges from the middle and bottom of Table 2 is in line with the findings of Campbell et al. (1997) and Mills and Jordanov (2000), since the cross-autocorrelations below the diagonal are larger than those above the diagonal. For example, the first-order autocorrelation between last week's return on portfolio 5 and this week's return on portfolio 1 is 0.1955 , while the first-order autocorrelation between last week's return on portfolio 1 and this week's return on portfolio 5 is -0.17 . 
Table 2. Cross-autocorrelation matrices of size portfolios

\begin{tabular}{|c|c|c|c|c|c|}
\hline \multicolumn{6}{|c|}{$\hat{Y}_{0}$} \\
\hline$i, j$ & 1 & 2 & 3 & 4 & 5 \\
\hline 1 & 1 & 0.821908 & 0.745567 & 0.645361 & 0.582567 \\
\hline 2 & 0.821908 & 1 & 0.945711 & 0.884512 & 0.869802 \\
\hline 3 & 0.745567 & 0.945711 & 1 & 0.712678 & 0.675678 \\
\hline 4 & 0.645361 & 0.884512 & 0.712678 & 1 & 0.803565 \\
\hline 5 & 0.582567 & 0.869802 & 0.675678 & 0.803565 & 1 \\
\hline \multicolumn{6}{|c|}{$\hat{Y}_{1}$} \\
\hline$i, j$ & 1 & 2 & 3 & 4 & 5 \\
\hline 1 & 0.0745 & 0.0671 & 0.0355 & 0.0289 & -0.1734 \\
\hline 2 & 0.0898 & 0.0881 & 0.0544 & 0.0431 & 0.0291 \\
\hline 3 & 0.1328 & 0.1187 & 0.0643 & 0.0501 & 0.0432 \\
\hline 4 & 0.1678 & 0.1329 & 0.1129 & 0.1034 & 0.0991 \\
\hline 5 & 0.1955 & 0.1622 & 0.1591 & 0.1378 & 0.1298 \\
\hline \multicolumn{6}{|c|}{$\hat{Y}_{2}$} \\
\hline$i, j$ & 1 & 2 & 3 & 4 & 5 \\
\hline 1 & -0.0159 & -0.0145 & -0.0109 & -0.0091 & -0.0049 \\
\hline 2 & -0.0203 & -0.0199 & -0.0162 & -0.0191 & -0.0156 \\
\hline 3 & -0.0117 & -0.0139 & -0.0913 & -0.0761 & -0.0991 \\
\hline 4 & -0.0302 & -0.0110 & -0.0583 & -0.0671 & -0.0803 \\
\hline 5 & -0.0044 & -0.0017 & -0.0671 & -0.0511 & -0.0669 \\
\hline
\end{tabular}

Table 3 reports the difference between the autocorrelation matrices and their transposes, i.e. $\hat{Y}_{k}-\hat{Y}_{k}$. As in Mills and Jordanov (2000), we observe that a particular pattern emerges for both the first-order and second-order serial correlation leading to the conclusion that the correlation between the one period lagged returns of the large size portfolios and the contemporaneous returns of the small size portfolios are always larger than the correlation between the last week's small size portfolio returns and the contemporaneous returns of the large size equity portfolio.

Table 3. Asymmetry of cross-correlation matrices

\begin{tabular}{|c|c|c|c|c|c|}
\hline \multicolumn{6}{|c|}{$\hat{Y}_{1}-\hat{Y}_{1}$} \\
\hline$i, j$ & 1 & 2 & 3 & 4 & 5 \\
\hline 1 & 0 & -0.0227 & -0.0973 & -0.1389 & -0.3689 \\
\hline 2 & 0.0227 & 0 & -0.0643 & -0.0898 & -0.1331 \\
\hline 3 & 0.0973 & 0.0643 & 0 & -0.0628 & -0.1159 \\
\hline 4 & 0.1389 & 0.0898 & 0.0628 & 0 & -0.0387 \\
\hline 5 & 0.3689 & 0.1331 & 0.1159 & 0.0387 & 0 \\
\hline \multicolumn{6}{|c|}{$\hat{Y}_{2}-\hat{Y}_{2}$} \\
\hline$i, j$ & 1 & 2 & 3 & 4 & 5 \\
\hline 1 & 0 & -0.0058 & -0.0008 & -0.0211 & -0.0093 \\
\hline 2 & 0.0058 & 0 & -0.0023 & -0.0081 & -0.0139 \\
\hline 3 & 0.0008 & 0.0023 & 0 & -0.0178 & -0.0320 \\
\hline 4 & 0.0211 & 0.0081 & 0.0178 & 0 & -0.0292 \\
\hline 5 & 0.0093 & 0.0139 & 0.0320 & 0.0292 & 0 \\
\hline
\end{tabular}

Lo and MacKinlay (1990) have put forward as possible explanation for this apparent controversial evidence of 'cross-effects' the existence of contrarian strategies by investors. Such contrarian strategies are considered to be successful in the presence of negative autocorrelation and they are amount to the argument that investors in the stock market tend to overreact to information, as we have already discussed in our introduction. Contrarian 
strategies are adopted when in the presence of negative correlation in the asset returns, investors earn excess positive excess returns by selling 'winners' and buying 'losers'. However, Boudoukh et al. (1994), argue that negative autocorrelation is not a dominant feature of the individual size-sorted equity portfolios and they show that the asymmetric cross-autocorrelations may be the outcome of the combination of positive own-autocorrelations and high contemporaneous correlation between portfolios.

\section{Cointegration and the Lead-Lag Relationship}

Kanas and Kouretas (2005) have developed a theoretical framework which provides the conditions under which cointegration entails the existence of a lead-lag effect. Their basic argument is that in contrast to correlation-based studies which only lead to short-run relationships, existence of cointegration between the size-sorted portfolios can provide more accurate predictions of future asset prices by exploiting the resulted error correction models. Their analysis leads to the derivation of a long-run one way information flow from large- to small-firm portfolios. By adopting the approach developed by Jegadeesh and Titman (1995) who employ a single factor model and assume that lagged factor shocks affect the current returns of small size portfolios.

Kanas and Kouretas (2005) show that there is compatibility between a lead-lag relationship and cointegration between the lagged price of large-firm portfolios and the contemporaneous price of small-firm portfolio. They prove that in case that a lead-lag effect exists then we can formulate a regression equation with the price of the small capitalization as the dependent variable and the lagged portfolio price of the large capitalization firm, a white noise common factor term and a nonstationary disturbance term. The crucial point in their analysis is that the existence of the lead-lag relationship implies the existence of the common factor term. Thus, if the idiosyncratic term is sufficiently small and the common factor is sufficiently large then we have a regression between the two portfolio prices. Kanas and Kouretas (2005) therefore, argue that cointegration between the current portfolio price of small-size firm and the lagged portfolio price of large-size firm can be considered that a long-run lead-lag relationship exists between prices of size-sorted portfolios.

The first step of our analysis is to examine, whether the series under consideration are stationary. For this purpose we apply the Elliot et al. (1996) GLS augmented Dickey-Fuller test (DF-GLS ${ }_{\mathrm{u}}$ ) and $\mathrm{Ng}$ and Perron (2001) GLS versions of the modified Phillips-Perron (1988) tests $\left(M Z_{a}^{G L S}\right.$ and $\left.M Z_{t}^{G L S}\right)$. These tests modify conventional unit root tests in order to derive tests that have both better size and power. For robustness, we then apply the Kwiatkowski et al. (1992) KPSS test for the null hypothesis of level or trend stationarity against the alternative of non-stationarity. The results of the unit root and stationarity tests are presented in Table 4. The results show that we are unable to reject the null hypothesis of non-stationarity with the DF-GLS $\mathrm{u}_{\mathrm{u}}$ and $M Z_{a}^{G L S}$ and $M Z_{t}^{G L S}$ tests and we reject the null hypothesis of stationarity with the KPSS test for the levels of both

series. The results are reversed when we take the first difference of each exchange rate series which leads us to the conclusion that all variables are realizations of $I(1)$ processes.

Table 4. Unit roots and stationarity tests

\begin{tabular}{|c|c|c|c|c|c|c|}
\hline \multirow[t]{2}{*}{ Variable } & \multicolumn{2}{|c|}{$D F-G L S_{u}$} & \multirow[t]{2}{*}{$M Z_{a}^{G L S}$} & \multirow[t]{2}{*}{$M Z_{t}^{G L S}$} & \multicolumn{2}{|c|}{$K P S S$} \\
\hline & $t_{\mu}$ & $t_{\tau}$ & & & $\eta_{\mu}$ & $\eta_{\tau}$ \\
\hline \multirow{2}{*}{$p_{1}$} & -0.33 & -1.65 & -0.41 & -0.39 & $0.903^{*}$ & $0.289^{*}$ \\
\hline & [6] & [6] & [5] & [5] & & \\
\hline \multirow[t]{2}{*}{$p_{2}$} & -1.23 & -1.45 & -1.25 & -1.11 & $1.125^{*}$ & $0.345^{*}$ \\
\hline & [7] & [7] & [8] & [8] & & \\
\hline \multirow[t]{2}{*}{$p_{3}$} & -0.15 & -1.78 & -0.89 & -0.56 & $1.342 *$ & $0.278^{*}$ \\
\hline & [5] & [5] & [4] & [4] & & \\
\hline \multirow{2}{*}{$p_{4}$} & -1.12 & -0.67 & -1.14 & -1.02 & $0.898^{*}$ & $0.451^{*}$ \\
\hline & [3] & [3] & [5] & [3] & & \\
\hline \multirow[t]{2}{*}{$p_{5}$} & 1.53 & -1.44 & -1.60 & -1.56 & $1.657^{*}$ & $0.245^{*}$ \\
\hline & {$[0]$} & {$[0]$} & [1] & [1] & & \\
\hline
\end{tabular}

Notes. $p_{1}, p_{2}, p_{3}, p_{4}, p_{5}$, are, respectively, the price of portfolios 1, 2, 3, 4 and 5 . 
- The $D F-G L S_{u}$ is due to Elliot et al. (1996) and Elliott (1999) is a test with an unconditional alternative hypothesis. The standard Dickey-Fuller tests are detrended (with constant or constant and trend). The critical values for the $D F-G L S_{u}$ test at the $5 \%$ significance level are:-2.73 (with constant) and -3.17 (with constant and trend), respectively (Elliott, 1999).

- $M Z_{a}$ and $M Z_{t}$ are the Ng and Perron (2001) GLS versions of the Phillips-Perron tests. The critical values at 5\% significance level are: -8.10 and -1.98 (with constant), respectively ( $\mathrm{Ng}$ and Perron, 2001, Table 1).

- $\quad \eta_{\mu}$ and $\eta_{\tau}$ are the KPSS test statistics for level and trend stationarity respectively (Kwiatkowski et al., 1992). For the computation of these statistics a Newey and West (1994) robust kernel estimate of the "long-run" variance is used. The kernel estimator is constructed using a quadratic spectral kernel with VAR(l) pre-whitening and automatic data-dependent bandwidth selection [see, Newey and West, 1994 for details]. The 5\% critical values for level and trend stationarity are 0.461 and 0.148 respectively, and they are taken from Sephton (1995, Table 2).

(*) indicates significance at the $95 \%$ confidence level.

Given these findings for the stochastic properties of the time series we then consider the case of cointegration. To this end we test for pairwise cointegration between the current price of a small-size portfolio and the lagged price of a large-size portfolio. This is done for all possible pairs using the Philips-Hansen (1990) single equation cointegration methodology. These tests are conducted for the period March 1997 to December 2013, reserving the 52 weeks of 2014 (last year of our sample) for out-of-sample forecasting. The null hypothesis of the Philips-Hansen (1990) cointegration test is that of no cointegration. This approach is an appropriate one for testing pairwise cointegration since it is a Fully-Modified OLS semi-parametric method that fully accommodates any moving average effects and which is asymptotically equivalent to the Full Information Maximum Likelihood estimation, and which yields asymptotically optimal estimates. In addition, this methodology uses the same non-parametric correction for the presence of serial correlation and heteroskedasticity in the residuals of the OLS estimates, as in the Phillips and Perron unit root tests. Finally, it uses a normalized non-parametric estimate of the long-run covariance to deal with the endogeneity problem. Unlike the OLS the FM-OLS estimates have both standard $t$-distributions and $t$-tests.

Table 5 reports are cointegration results. All cointegration tests are based on the current price of portfolio $i$ and the lagged price of portfolio $j, i, j=1, . .5, j>i$. The results show that cointegration exists between the contemporaneous price of portfolio 1 (smallest capitalization portfolio) and the lagged price of portfolios 4 and 5 (largest capitalization portfolios). In addition cointegration was established for the case of the current price of portfolio 2 and portfolio 5. Therefore, we argue that contemporaneous small-size portfolio prices cointegrate with lagged prices of large-size portfolios and therefore this is compatible with the existence of the lead-lag effect.

Table 5. Phillips-Hansen tests for cointegration

\begin{tabular}{|c|c|c|c|c|c|}
\hline \multicolumn{6}{|c|}{$P_{i, t}=b_{0}+b_{1} P_{j, t-1}, i, j=1, \ldots, 5, i>j$} \\
\hline & Portfolio 1 & Portfolio 2 & Portfolio 3 & Portfolio 4 & Portfolio 5 \\
\hline Portfolio 1 & ................ & -1.687545 & -1.754461 & $-3.689012 *$ & $-3.957790 *$ \\
\hline Portfolio 2 & & ……… & -1.445679 & -2.226678 & $-3.890022 *$ \\
\hline Portfolio 3 & & & .............. & -2.157890 & -2.525796 \\
\hline Portfolio 4 & & & & ............... & -2.163377 \\
\hline Portfolio 5 & & & & & ……… \\
\hline
\end{tabular}

Notes. The table reports the modified augmented Phillips-Perron $Z(\alpha)$ test statistics calculated on the residuals of the corresponding cointegration regression estimated using the Phillips-Hansen Fully Modified-OLS method. The null hypothesis is that of no cointegration. The 5\% critical value is -20.4935 (Phillips \& Ouliaris; 1990, Table $\mathrm{Ib}$ ). The data is weekly and therefore the sample period runs from the $1^{\text {st }}$ week of 1997 to the $52^{\text {nd }}$ week of 2013.

(*) denotes statistical significance at the $5 \%$ level. Bolded test statistics indicate portfolio pairs for which there is cointegration.

Given the evidence in favour of cointegration between the current price of portfolio 1 and the lagged price of portfolios 4 and 5 as well as of portfolio 2 and portfolio 5 we then turn to the estimation of the long-run coefficients of the corresponding cointegration vectors. The estimated coefficients are presented in Table 6 . We 
also report asymptotic t-statistics below the estimated coefficient. The upper diagonal of Table 6 reports the coefficients for cointegrating relations in which the large capitalization portfolio is the independent variable. The estimated coefficients reported in the upper diagonal are all statistically significant and therefore we conclude that the large capitalization portfolio prices are long-run 'forcing' variables for small capitalization portfolio prices. The overall conclusions are therefore in line with Lo and MacKinley (1990), Mills and Jordanov (2000) and Grieb and Reyes (2002) who argue that there is lead-lag effect from large- to small-firm portfolios but not from the small- to large-firm portfolios. Furthermore, our results for the Cyprus capital market are in line with those of Kanas and Kouretas (2005) who provide empirical support for the existence of a long-run lead-lag effect in the UK capital market.

Table 6. Estimation of the long-run coefficients of the cointegrating relations

\begin{tabular}{|c|c|c|c|c|c|}
\hline \multicolumn{6}{|c|}{ Independent Variable } \\
\hline Dependent Variable & Portfolio 1 & Portfolio 2 & Portfolio 3 & Portfolio 4 & Portfolio 5 \\
\hline Portfolio 1 & ............... & - & - & $2.1(5.1)^{*}$ & $2.6(4.9)^{*}$ \\
\hline Portfolio 2 & - & ….......... & - & - & $2.6(5.5)^{*}$ \\
\hline Portfolio 3 & - & - & .............. & - & - \\
\hline Portfolio 4 & - & - & - & .............. & - \\
\hline Portfolio 5 & - & - & - & - & .............. \\
\hline
\end{tabular}

Notes. The reported coefficients are the long-run coefficients of the cointegration vectors for the pairs of portfolios for which cointegration is found in Table 5. Asymptotic $t$-statistics are reported in parentheses next to each long-run coefficient. The data is weekly and therefore the sample period runs from the $1^{\text {st }}$ week of 1997 to the $52^{\text {th }}$ week of 2013 . $\left(^{*}\right)$ denote statistical significant coefficients at the $5 \%$ level of significance.

\section{Error Correction Models and Out-of-Sample Forecasting}

This part of our paper considers the error correction models which are derived from those cases where cointegration has been established and the long-run parameters have been estimated. Our purpose then, is to obtain out-of-sample forecasts for the returns of small-firm portfolios for the period January 2014 to December 2014. The error correction model is based on the estimated cointegrating relationships from the estimated equations for the period March 1997 to December 2013. The error correction model is given by equation (3):

$$
\Delta x_{t}=c+\sum_{i=1}^{p} \Delta x_{t-i}+\sum_{i=1}^{k} \Delta y_{t-i}+\delta e c t_{t-1}+u_{t}
$$

where $\Delta x_{t}$ is the portfolio returns, and $e c t_{t-1}$ is the lagged error correction term estimated using the Phillips-Hansen (1990) approach. As it is always the case the coefficient of the error correction term, $\delta$, is expected to be negative and statistically significant. Table 7 reports the results from the estimation of the error correction models for the period March 1997 to December 2013. It is clear from the estimated coefficient of the error correction term in all case is negative and statistically significant and thus we are entitled to use the error correction models in conducting the out-of-sample forecasting.

Table 7. Error correction models: 1997.01-2013.52

\begin{tabular}{|c|c|c|c|c|c|c|c|c|}
\hline \multicolumn{2}{|l|}{ Model } & \multirow[b]{2}{*}{ Model Order } & \multirow[t]{2}{*}{$c$} & \multirow[t]{2}{*}{$E C T_{t-1}$} & \multirow[t]{2}{*}{$\Delta x_{t-1}$} & \multirow[t]{2}{*}{$\Delta x_{t-2}$} & \multirow[t]{2}{*}{$\Delta y_{t-1}$} & \multirow[t]{2}{*}{$\Delta y_{t-2}$} \\
\hline Dependent Variable $\left(\Delta x_{t}\right)$ & Independent Variable $\left(\Delta y_{t}\right)$ & & & & & & & \\
\hline \multirow[t]{2}{*}{ Portfolio 1} & Portfolio 5 & $(2,1)$ & $\begin{array}{l}0.27 * \\
(6.83)\end{array}$ & $\begin{array}{c}-0.028 * \\
(-4.12)\end{array}$ & $\begin{array}{l}0.41 * \\
(7.13)\end{array}$ & $\begin{array}{l}0.19 * \\
(3.18)\end{array}$ & $\begin{array}{l}0.15^{*} \\
(3.78)\end{array}$ & - \\
\hline & Portfolio 4 & $(2,2)$ & $\begin{array}{c}0.39 \\
(1.05)\end{array}$ & $\begin{array}{c}-0.034 * \\
(-3.56)\end{array}$ & $\begin{array}{l}0.44 * \\
(5.01)\end{array}$ & $\begin{array}{l}0.20 * \\
(4.19)\end{array}$ & $\begin{array}{l}0.51 * \\
(4.90)\end{array}$ & $\begin{array}{l}0.34 * \\
(3.10)\end{array}$ \\
\hline Portfolio 2 & Portfolio 5 & $(2,1)$ & $\begin{array}{l}0.37 * \\
(3.25) \\
\end{array}$ & $\begin{array}{c}-0.040 * \\
(-5.03)\end{array}$ & $\begin{array}{l}0.71 * \\
(8.01)\end{array}$ & $\begin{array}{l}0.33 * \\
(4.15) \\
\end{array}$ & $\begin{array}{l}0.49 * \\
(5.67) \\
\end{array}$ & - \\
\hline
\end{tabular}

Notes. $\mathcal{C}$ is the constant; ECT denotes the error correction term. $\left(^{*}\right)$ denotes statistical significance. The data is weekly and therefore the sample period runs from the $1^{\text {st }}$ week of 1997 to the $52^{\text {th }}$ week of 2013. 
The results of the out-of-sample forecasting are reported in Table 8 . These forecasts for the returns of portfolios have been obtained for the period January 2014 to December 2014. We have also obtained out-of-sample forecasts from the same dynamic equations without the inclusion of the error correction terms in order to compare the forecasting performance of the error correction models. We apply the Root Mean Squared Error (RMSE) and the evidence reported is that this measure is always smaller for the model with the error correction term than the model without this term. As a further check we employ the Wilcoxon's signed-rank suggested by Diebold and Mariano (1995). This is a nonparametric test for the null hypothesis that the difference between the RMSE of the two competing models is not statistically different than zero. The results of the Wilcoxon's test are given in Table 8 and we observe that the null hypothesis is rejected at the 5\% level of significance indicating that the RMSE of the model with the error correction has a smaller value and hence it provides more accurate out-of-sample forecasts than the model without the lead-lag effect included into it. This finding is consistent with the results of Kanas and Kouretas (2005) for the case of the UK stock market and Drakos (2015) for the Athens Stock Exchange which further confirms the relevance of cointegration in forecasting small-capitalisation portfolio returns. Furthermore, this result has practical implications for the investors, technical analysts, institutional investors and portfolio managers since more accurate out-of-sample forecasts can help them to design profitable investment strategies.

Table 8. Out-of-sample forecasting of 'small-firm' portfolio returns: 2014.01-2014.52

\begin{tabular}{llccc}
\hline & Model & RMSE from model & RMSE from model & Wilcoxon's signed rank test \\
with the $E C T$ & without the $E C T$ & \\
\hline Portfolio 1 & Independent Variable & 0.067 & 0.225 & $4.11[0.00]$ \\
& Portfolio 5 & 0.078 & 0.878 & $2.23[0.00]$ \\
Portfolio 2 & Portfolio 4 & 0.051 & 0.345 & $3.59[0.00]$ \\
\hline
\end{tabular}

Notes. Wilcoxon's signed rank test is a statistical criterion for the null hypothesis that the difference of the two RMSEs is not statistically significant against the alternative that the difference of the two RMSEs is statistically significant, i.e. $H_{0}$ : the two RMSEs are equal against $H_{1}$ : the two RMSEs are not equal. The data is weekly and therefore the sample period runs from the $1^{\text {st }}$ week of 2014 to the $52^{\text {nd }}$ week of 2014.

\section{Summary and Concluding Remarks}

This paper provides evidence that a lead-lag effect between the contemporaneous price of the small-size portfolio and the lagged price of the large-size portfolio for the case of an emerging capital market, the Cyprus Stock Exchange. The analysis examines the presence of this important lead-lag effect in both the short-run and the long-run. In the first part, we follow Lo and MacKinlay (1990) and Mills and Jordanov (2000) and we calculate cross-correlations between the five size-sorted equally weighted weekly portfolios of the CSE and it is shown that there is a statistically significant short-run lead-lag effect implying that there is lagged information transmission from the returns of the large capitalization portfolio to the small capitalization portfolio.

In addition, we have applied the single factor model by Kanas and Kouretas (2005) to investigate the existence of a lead-lag effect in a long-run framework. Evidence of cointegration between the size-sorted portfolios is taken to imply a lead-lag relationship. The results show that there is evidence between the prices of small- and large-firm portfolio. Furthermore, this lead-lag effect is shown to hold from the large-firm portfolio to the small-firm portfolio but not the opposite. Finally, with the application of the Wilcoxon's nonparametric exact finite-sample test we show that the RMSE of the error correction model is smaller that the competing dynamic model without the error correction term and this implies that we obtain more accurate out-of-sample forecasts with the dynamic model that includes the lead-lag effect.

The overall results suggest that the existence of lead-lag effect in the Cyprus Stock Exchange holds for both the short and long-run, confirming the results of previous studies carried out for mature and several emerging markets. Thus, for both the short- and long-run, our results support the existence of one-way information flow from large- to small-capitalization portfolios. Furthermore, these findings suggest that the capital market of Cyprus appears to be informationally inefficient since based on this lead-lag effect forecastibility of assets' returns is feasible. Our results may be of interest to investors, institutional investors, technical analysts and portfolio managers who are interested in finding profitable portfolio strategies in the Cyprus Stock Exchange based on past stock returns. In the aftermath of the financial crisis of the financial crisis of 2007-2009 and the subsequent Eurozone debt crisis, the Cyprus capital market is expected to attract substantial capital flows in an 
effort to boost economic growth after the negative effects of the collapse of its banking sector, the bail-in scheme that led most of the households and firms to lose a substantial part of their savings and the subsequent lifting of capital controls in April 2015. In addition, the results of the present analysis will also be helpful in modeling asset prices since it provides additional relevant variables that we could use to explain asset returns.

\section{Acknowledgments}

An earlier version of this paper was presented at working Seminars at Audencia Nantes School of Management, Athens University of Economics and Business, Central Bank of Cyprus, Technical University of Cyprus, University of Birmingham and University of Piraeus and thanks are due to seminar participants for many helpful comments and discussions. Kouretas acknowledges financial support from a Marie Curie Transfer of Knowledge Fellowship of the European Community's Sixth Framework Programme under contract number MTKD-CT-014288, as well as from the Research Committee of the University of Crete under research grant 2257. We would also like to thank without implicating Michael Argyrou, Efrem Castelnuovo, Manthos Delis, Dimitris Georgoutsos, Shawkat Hammoudeh, Iftekhar Hasan, Emilios Galariotis, Dimitris Moschos, Ekaterini Panopoulou, George Syrichas, Chris Tsoumas, Leonidas Zarangas and Stavros Zenios for numerous helpful comments on an earlier draft of this paper. We also thank Argiris Volis for excellent research assistance. Finally, we thank the Editor and an anonymous referee for many valuable comments that improved the manuscript substantially. The usual caveat applies.

\section{References}

Altay, E. (2004). Cross-autocorrelation between small and large cap portfolios in the German and Turkish stock markets. Journal of Financial Management and Analysis, 17, 77-92.

Antoniou, A., Ergul, N., \& Holmes, P. (1997). Market efficiency, thin trading and non-linear behaviour: Evidence from an emerging market. European Financial Management, 3, 175-190. http://dx.doi.org/10.1111/1468-036X.00038

Antoniou, A., Galariotis, E. C., \& Spyrou, S. I. (2005). Contrarian profits and the overreaction hypothesis: The case of the Athens Stock Exchange. European Financial Management, 11, 71-98. http://dx.doi.org/10.1111/j.1354-7798.2005.00276.x

Asness, C. (1994). The power of past stock returns to explain future stock returns. Working Paper, AQR Capital Management.

Badrinath, S. G., Kale, J. R., \& Noe, T. H. (1995). Of shepherds, sheep, and the cross correlations in equity returns. Review of Financial Studies, 8, 401-430. http://dx.doi.org/10.1093/rfs/8.2.401

Bluedorn, J., Duttagupta, R., Guajardo, J., \& Topalova, P. (2013). Capital flows are fickle: Anytime, anywhere. IMF Working Paper WP/13/183. Washington: International Monetary Fund, August.

Bossaerts, P. (1988). Common stationary components of asset prices. Journal of Economic Dynamics and Control, 12, 347-364. http://dx.doi.org/10.1016/0165-1889(88)90045-0

Boudoukh, J., Richardson, M. P., \& Whitelaw, R. F. (1994). A tale of three schools: Insights on autocorrelations of short-horizon stock returns. Review of Financial Studies, 7, 539-573. http://dx.doi.org/10.1093/rfs/7.3.539

Campbell, J. Y., \& Shiller, R. J. (1988). Interpreting cointegrated models. Journal of Economic Dynamics and Control, 12, 505-522. http://dx.doi.org/10.1016/0165-1889(88)90053-X

Campell, J. Y., Lo, A. W., \& MacKinlay, A. C. (1997). The Econometrics of Financial Studies. Princeton University Press, Princeton NJ.

Chan, K. C. (1988). On contrarian investment strategy. Journal of Business, 61, 147-163. http://dx.doi.org/10.1086/296425

Chan, K. C. (1992). A further analysis of the lead-lag relation between the cash market and stock index futures market. Review of Financial Studies, 5, 123-152. http://dx.doi.org/10.1093/rfs/5.1.123

Chan, K. C. (1993). Imperfect information and cross-autocorrelation among stock prices. Journal of Finance, 48, 1211-1229. http://dx.doi.org/10.1111/j.1540-6261.1993.tb04752.x

Chang, E. C., McQueen, G. R., \& Pinegar, M. J. (1999). Cross autocorrelation in Asian stock markets. Pacific-Basin Finance Journal, 7, 471-493. http://dx.doi.org/10.1016/S0927-538X(99)00021-9

Cheung, Y. W., \& Ng, L. K. (1996). A causality-in-variance test and its application to financial market prices. 
Journal of Econometrics, 72, 33-48. http://dx.doi.org/10.1016/0304-4076(94)01714-X

Cho, J. W., Shin, J., \& Singh, R. (1999). Endogenous informed trading in the presence of trading costs: Theory and evidence. Journal of Financial Markets, 2, 273-305. http://dx.doi.org/10.1016/S1386-4181(99)00003-8

Chrisostomidou, E., Georgoutsos, D., Kanas, A., Kouretas, G. P., \& Siakalli, C. (2006). Cyprus Stock Exchange: Institutional Framework, Evaluation and Prospects of an Emerging Capital Market. Nicosia: Cyprus Research Promotion Foundation.

Chui, A. C. W., \& Kwok, C. C. Y. (1988). Cross-autocorrelation between A shares and B shares in the Chinese stock market. Journal of Financial Research, 21, 333-354.

Conrad, J., \& Kaul, G. (1988). Time-variation in expected returns. Journal of Business, 61, 409-425. http://dx.doi.org/10.1086/296441

Conrad, J., \& Kaul, G. (1989). Mean-reversion in short-horizon expected returns. Review of Financial Studies, 2 , 225-240. http://dx.doi.org/10.1093/rfs/2.2.225

Conrad, J., \& Kaul, G. (1998). An anatomy of trading strategies. Review of Financial Studies, 11, 489-519. http://dx.doi.org/10.1093/rfs/11.3.489

Conrad, J., Gultekin, M. N., \& Kaul, G. (1991). Asymmetric predictability of conditional variances. Review of Financial Studies, 4, 597-622. http://dx.doi.org/10.1093/rfs/4.4.597

Conrad, J., Hameed, A., \& Niden, C. (1994). Volume and autocovariances in short-horizon individual security returns. Journal of Finance, 49, 1305-1329. http://dx.doi.org/10.1111/j.1540-6261.1994.tb02455.x

Constantinou, P., Charalambous, A., \& Manison, L. (2008). Can Cyprus cope inside the EMU? Cyprus Economic Policy Review, 2, 63-79.

Diamandis, P. F. (2014). Modelling volatility and testing for efficiency in emerging capital markets: The case of the Cyprus Stock Exchange. Department of Business Administration, AUEB, Working Paper.

Diebold, F. X., \& Mariano, R. S. (1995). Comparing predictive accuracy. Journal of Business and Economic Statistics, 13, 253-263.

Drakos, A. A. (2015). Does the relationship between small and large portfolios' returns confirm the lead-lag effect? Evidence from the Athens Stock Exchange. Research in International Business and Finance, forthcoming. http://dx.doi.org/10.1016/j.ribaf.2015.05.002

Elliott, G. (1999). Efficient tests for a unit root when the initial observation is drawn from its unconditional distribution. International Economic Review, 44, 767-784. http://dx.doi.org/10.1111/1468-2354.00039

Elliott, G., Rothenberg, J. T., \& Stock, J. H. (1996). Efficient tests for an autoregressive unit root. Econometrica, 64, 813-836. http://dx.doi.org/10.2307/2171846

Forbes, K. J., \& Warnock, F. E. (2012). Capital flow waves: Surges, stops, flight, and retrenchment. Journal of International Economics, 88, 233-251. http://dx.doi.org/10.1016/j.jinteco.2012.03.006

Giannelis, N., \& Kouretas, G. P. (2009). From the Cyprus Pound to the Euro: How close is the Central Parity Rate to the Equilibrium Rate? Department of Business Administration, AUEB, Working Paper.

Granger, C. W. J. (1986). Developments in the study of cointegrated economic variables. Oxford Bulletin of Economics and Statistics, 48, 213-228. http://dx.doi.org/10.1111/j.1468-0084.1986.mp48003002.x

Grieb, T., \& Reyes, M. G. (2002). The temporal relationship between large-and small-capitalisation stock returns: Evidence from the UK. Review of Financial Economics, 11, 109-118. http://dx.doi.org/10.1016/S1059-0560(02)00104-1

Hou, K. (2007). Industry information diffusion and the Lead-lag effect in stock returns. Review of Financial Studies, 20, 1113-1138. http://dx.doi.org/10.1093/revfin/hhm003

Jegadeesh, N. (1990). Evidence of predictable behaviour of security returns. Journal of Finance, 45, 881-898. http://dx.doi.org/10.1111/j.1540-6261.1990.tb05110.x

Jegadeesh, N., \& Titman, S. (1993). Returns to buying winners and selling losers: Implications for stock market efficiency. Journal of Finance, 48, 65-91. http://dx.doi.org/10.1111/j.1540-6261.1993.tb04702.x

Jegadeesh, N., \& Titman, S. (1995). Overreaction, delayed reaction, and contrarian profits. Review of Financial Studies, 8, 973-993. http://dx.doi.org/10.1093/rfs/8.4.973

Kanas, A. (2004). Lead-lag effects in the mean and variance of returns of size-sorted UK equity portfolios. 
Empirical Economics, 29, 575-592. http://dx.doi.org/10.1007/s00181-004-0199-3

Kanas, A., \& Kouretas, G. P. (2005). A cointegration approach to the lead-lag effect among size-sorted equity portfolio. International Review of Economics and Finance, 14, 181-201. http://dx.doi.org/10.1016/j.iref.2003.12.004

Kang, J., Liu, M. H., \& Ni, S. X. (2002). Contrarian and momentum strategies in the China stock market: 1993-2000. Pacific-Basin Finance 243-265. http://dx.doi.org/10.1016/S0927-538X(02)00046-X

Karmakar, M. (2010). Information transmission between small and large stocks in the National Stock Exchange in India: An empirical study. The Quarterly Review of Economics and Finance, 50, 110-120. http://dx.doi.org/10.1016/j.qref.2009.09.007

Kwiatkowski, D., Phillips, P. C. B., Schmidt, P., \& Shin, Y. (1992). Journal of Econometrics. Testing the null hypothesis of stationarity against the alternative of a unit root: How sure are we that economic time series have a unit root? Journal of Econometrics, 54, 159-178. http://dx.doi.org/10.1016/0304-4076(92)90104-Y

Kyriacou, G., \& Syrichas, G. (1999). EMU and the introduction of the euro: Macroeconomic implications for the Cyprus economy. Quarterly Economic Review, July, Central Bank of Cyprus.

Lehmann, B. (1990). Fads, martingales, and market efficiency. Quarterly Journal of Economics, 105, 1-28. http://dx.doi.org/10.2307/2937816

Levich, R., \& Thomas, L. (1993). The significance of technical trading-rule profits in the foreign exchange market: A bootstrap approach. Journal of International Money and Finance, 12, 451-474. http://dx.doi.org/10.1016/0261-5606(93)90034-9

Li, Y., Greco, J. F., \& Chavis, B. (1999). Lead-lag relations between A shares and H shares in the Chinese stock markets. Working Paper.

Lo, A., \& MacKinlay, C. (1988). Stock market prices do not follow random walks: evidence from a simple specification test. Review of Financial Studies, 1, 41-66. http://dx.doi.org/10.1093/rfs/1.1.41

Lo, A., \& MacKinlay, C. (1990). When are contrarian profits due to stock market overreaction? Review of Financial Studies, 3, 175-206. http://dx.doi.org/10.1093/rfs/3.2.175

Marshall, P., \& Walker, E. (2002). Asymmetric reaction to information and serial dependence of short-run returns. Journal of Applied Economics, 5, 273-292.

Merton, R. C. (1987). A simple model of capital market equilibrium with incomplete information. Journal of Finance, 42, 483-510. http://dx.doi.org/10.1111/j.1540-6261.1987.tb04565.x

Mills, T. C., \& Jordanov, J. (2000). Lead-lag patterns between small and large size portfolios in the London stock exchange. Applied Financial Economics, 11, 489-495. http://dx.doi.org/10.1080/096031001752236771

Newey, W., \& West, K. (1994). Automatic lag selection in covariance matrix estimation. Review of Economic Studies, 61, 631-653. http://dx.doi.org/10.2307/2297912

$\mathrm{Ng}$, S., \& Perron, P. (2001). Lag length selection and the construction of unit root tests with good size and power. Econometrica, 69, 1519-1554. http://dx.doi.org/10.1111/1468-0262.00256

Orphanides, A. (2008). Preparing for the Euro-Perspectives from the monetary policy strategy in Cyprus. In K. Liebscher, J. Christl, P. Mooslechner, \& D. Ritzberger-Grunwald (Eds.), Currency and Competitiveness in Europe. Cheltenham: Edward Elgar. http://dx.doi.org/10.4337/9781848445093.00027

Pattichis, C., Maratheftis, M., \& Zenios, S. (2007). Economic Fundamentals and the Behavior of the Real Effective Exchange Rate of the Cyprus Pound. International Economic Journal, 21, 133-154. http://dx.doi.org/10.1080/10168730601181026

Phillips, P. C. B., \& Hansen, B. (1990). Statistical inference in instrumental variables regression with I(1) processes. Review of Economic Studies, 57, 99-125. http://dx.doi.org/10.2307/2297545

Phillips, P. C. B., \& Ouliaris, S. (1990). Asymptotic properties of residual based tests for cointegration. Econometrica, 58, 165-193. http://dx.doi.org/10.2307/2938339

Poshakwale, S., \& Theobald, M. (2004). Market capitalization, cross-correlations, the lead/lag structure and microstructure effects in the Indian stock market. Journal of International Financial Markets, Institutions and Money, 14, 385-400. http://dx.doi.org/10.1016/j.intfin.2003.12.001 
Powell, J. H. (2013). Advanced economy monetary policy and emerging market economies. Federal Reserve Bank of San Francisco 2013 Asia Economic Policy Conference: Prospects for Asia and the Global Economy, November.

Richardson, T., \& Peterson, D. R. (1999). The cross-autocorrelation of size-based portfolio returns is not an artifact of portfolio autocorrelation. Journal of Financial Research, 22, 1-13. http://dx.doi.org/10.1111/j.1475-6803.1999.tb00711.x

Sephton, P. S. (1995). Response surface estimates of the KPSS stationarity test. Economics Letters, 47, 255-261. http://dx.doi.org/10.1016/0165-1765(94)00561-F

Shaghil, A., \& Zlate, A. (2013). Capital flows to Emerging market economies: A brave new world? International Finance Discussion Papers 1081. Washington: Board of Governors of the Federal Reserve System, June.

Singh, A., \& Weisse, B. (1998). Emerging stock markets, portfolio capital flows and long-term economic growth: Micro and macroeconomic perspectives. World Economy, 26, 607-622.

Syrichas, G. (2008). Monetary policy strategy and the euro: Lessons from Cyprus. Cyprus Economic Policy Review, 2, 81-102.

Toth, B., \& Kertesz, J. (2006). Increasing market efficiency: Evolution of cross-correlations of stock returns. Physica A, 360, 505-515. http://dx.doi.org/10.1016/j.physa.2005.06.058

\section{Notes}

Note 1. Lo and Mackinlay (1988), Conrad and Kaul (1988, 1989), Conrad et al. (1991) and Conrad et al. (1994) are some of the studies that have provided evidence on stock return predictability. Boudoukh et al. (1994), Richardson and Peterson (1999) have also tested for a lead-lag relationship in the U.S. stock market, Mills and Jordanov (2000), Grieb and Ryes (2002) have conducted similar studies for the U.K. stock market while Chang et al. (1999) provide evidence of lead-lag effects in several Asian markets. Finally, Kanas and Kouretas (2005) provide evidence of a lead-lag relationship in a long-run framework.

Note 2. Toth and Kertesz (2006) analyze the temporal changes in the cross-correlations of returns using data from the NYSE and they show that lead-lag that the observed lead-lag effect between daily stock returns disappeared in less than 20 years.

Note 3. Recent evidence for the existence of a lead-lag pattern between small and large capitalization portfolios in emerging markets is provided by Drakos (2015) for the Athens Stock Exchange. Furthermore, with the use of the cross-autocorrelation approach Altay (2004) found evidence of a lead-lag relationship for the German and Turkish equity markets. Using the same approach Chang et al. (1999) provided evidence of lead-lag effects in several Asian markets, whereas Chui and Kwok (1998), Kang et al. (2002), Li et al. (2002) have identified such a lead-lag effect with the different types of stocks trade in the Chinese stock exchange market. In addition, Marshall and Walker (2002) and Poshakwale and Theobald (2004) using cross-autocorrelations also confirmed a short-run lead-lag relationship between large- and small-capitalization portfolios for the case of the Chilean stock market and the Indian stock market. Finally, Karmakar (2010) investigates both casual and dynamic relationship between the large stocks and small stocks in the national stock exchange in India using daily index data on S\&P CNX.

Note 4. Kyriacou and Syrichas (1999), Pattichis et al. (2007), Constantinou et al. (2008), Orphanides (2008), Syrichas (2008), Giannelis and Kouretas (2009) are additional studies that examine the workings of the financial markets of Cyprus and the macroeconomic environment.

Note 5. Conrad and Kaul (1988, 1989), Chan (1988), Jegadeesh (1990), Lehmann (1990) Jegadeesh and Titman (1993), Levich and Thomas (1993) and Asness (1994) are other studies that discuss these issues.

Note 6. In related studies Chan (1992) finds asymmetric lead-lag relation between futures and the cash index and Chan (1993) shows that existence of partial impounding of information in security prices results in non-zero cross autocorrelations in security price differentials. Kanas (2004), examines the existence of short-run lead-lag relation in the UK stock market by applying the Cross Correlation Function approach (1996). Cho et al. (1999) argue that an alternative explanation of the existence of an asymmetric cross-correlation as a result of the strategic entry decisions of informed investors.

Note 7. We use weekly, as opposed to monthly or daily returns, to estimate the lead-lag effect. Compared to monthly returns, weekly returns offer improved estimation accuracy. Furthermore, even though daily returns can 
improve precision, they may also introduce confounding microstructure influences (for example bid-ask bounce and nonsychronous trading). For these reasons we consider weekly returns to be the natural compromise.

Note 8 . The construction of five portfolios is dictated by the small number of years that the CSE operates. However, the creation of five instead of ten portfolios has the advantage that may lead to clear cut distinctions among the portfolios with respect to size and thus to avoid mixed results due to overlapping at the border. The sample is restricted to those firms that had positive market-to-book values and borrowing ratios.

Note 9. Lo and MacKinlay's (1990) results were based on equally weighted size-sorted portfolios.

Note 10. Granger (1986), Bossaerts (1988), Campbell and Shiller (1988) are among several studies that examine analyzed the issue of cointegration and asset prices.

Note 11. In contrast, Grieb and Reyes (2002) found evidence of a short-two-way information flow.

Note 12. We have also conducted a robustness analysis by splitting the sample before and after the financial crisis (September 2008, Lehman Brothers bankruptcy) and the sovereign European debt crisis (for which the starting point is taken to be November 2009 when the Greek debt problems came to the surface). For each case we employed both approaches and we found no evidence that the lead-lag effect is more pronounced in the pre-or post-crisis period. To save space the results are available upon request.

\section{Copyrights}

Copyright for this article is retained by the author(s), with first publication rights granted to the journal.

This is an open-access article distributed under the terms and conditions of the Creative Commons Attribution license (http://creativecommons.org/licenses/by/3.0/). 